\title{
Morphological Study and Dielectric Behavior of Nonisothermally Crystallized Poly(ethylene naphthalate) Nanocomposites as a Function of Graphene Content
}

\author{
Adriana B. Espinoza-Martinez, ${ }^{1}$ Felipe Avalos-Belmontes, ${ }^{2}$ Luis F. Ramos-de Valle, \\ Pedro A. Espinoza-Martinez, ${ }^{1}$ Carlos A. Avila-Orta, ${ }^{1}$ \\ Florentino Soriano-Corral, ${ }^{1}$ José M. Mata-Padilla, ${ }^{1}$ and María M. Tellez-Rosas ${ }^{2}$ \\ ${ }^{1}$ Centro de Investigación en Química Aplicada, Boulevard Enrique Reyna 140, 25294 Saltillo, COAH, Mexico \\ ${ }^{2}$ Departamento de Polímeros Facultad de Ciencias Químicas, Universidad Autónoma de Coahuila, José Cárdenas Valdés S/N, \\ 25280 Saltillo, COAH, Mexico
}

Correspondence should be addressed to Adriana B. Espinoza-Martinez; adriana.espinoza@ciqa.edu.mx and Felipe Avalos-Belmontes; favalos@uadec.edu.mx

Received 21 April 2016; Accepted 26 September 2016

Academic Editor: Yasuhiko Hayashi

Copyright (C) 2016 Adriana B. Espinoza-Martinez et al. This is an open access article distributed under the Creative Commons Attribution License, which permits unrestricted use, distribution, and reproduction in any medium, provided the original work is properly cited.

\begin{abstract}
Morphological evolution and dielectric properties of poly(ethylene naphthalate)- (PEN-) graphene nanocomposites nonisothermally crystallized have been investigated. PEN-graphene nanocomposites containing $0.01,0.025,0.05,0.075$, and $0.1 \mathrm{wt} \%$ of graphene were prepared by melt blending in a mini twin screw extruder. The results showed that graphene exhibited a superior influence on morphological and conformational structure of PEN during nonisothermal crystallization at low graphene contents. Crystallization temperature $\left(T_{c}\right)$ was found to be increased up to $18^{\circ} \mathrm{C}$ supporting the high nucleating activity of graphene layers. Wide angle X-ray diffraction (WAXD) and Fourier Transform Infrared Spectroscopy (FTIR) indicated that graphene modifies the conformation of PEN chains promoting crystallinity and favoring the evolution from $\alpha$ to $\beta$ crystalline form with homogeneous lamellar thickness. It may be attributed to the structural similarity between naphthalene rings and graphene structure and to $\pi$ $\pi$ interactions during nucleation. Dielectric behavior was found to be a function of graphene content where the nanocomposites changed from dielectric to low conducting material when passing from 0.075 to $0.1 \mathrm{wt} \%$ of graphene content. This phenomenon permits having a wide range of properties to fit a wide variety of applications required to store electrical energy of low voltage.
\end{abstract}

\section{Introduction}

Graphene has become one of the most important carbon materials due to its unique electronic, mechanical, and thermal properties [1]. In the last five years, graphene has been used to fabricate polymer nanocomposites, and they have shown very high performance for a wide variety of applications such as automotive, packaging, and electronics [2-4]. Due to its two-dimensional structure, the percolation threshold can be achieved at very low contents $(<0.1$ vol\%) that makes graphene a suitable carbon filler for electrostatic discharge and electromagnetic devices [5]. However, the use of polymeric nanocomposites in electronics is limited to a few plastics in combination with some conductive fillers. The characteristics sought in plastics intended for this use are gas barrier and corrosion and thermal and chemical resistance, as well as easy processing. Conductive nanocomposites based on engineering thermoplastics fulfill some of these features and could offer a wide range of advantages in electronic applications. Among these thermoplastics, semicrystalline polyesters such as poly(ethylene terephthalate) (PET) $[6,7]$ and poly(butylene terephthalate) (PBT) [8] have been widely used as structural materials in electrical, automotive, and electronic applications, and 
it has been reported that their use as matrix for electrical conductive nanocomposites is of great industrial relevance. Another engineering polyester is poly(ethylene naphthalate) (PEN) which is used as high-performance polymer with better mechanical, thermal, chemical, and barrier properties than PET $[9,10]$. Resulting from the increased chain stiffness PEN can be used as stable substrate in electronic and optoelectronic devices, particularly electroluminescent display devices, such as organic light emitting diode displays (OLED displays) [11]. Another interesting characteristic of PEN is its ability to crystallize and gain certain properties absent in its amorphous state $[12,13]$. It has been reported that PEN has three different crystal morphologies know as $\alpha, \beta$, and $\gamma$ [14], which can be obtained depending of the crystallization conditions, for example, crystallization temperature, cooling rate, premelting temperature, and mechanical orientation. Recently, it was reported that carbon nanotubes induce $\beta$ crystals in PEN nanocomposites under isothermal [15] and nonisothermal conditions [16] at low nanotubes content. It was proposed that nanotubes act as templates and induce an aromatic self-assembly due to the $\pi$ interactions between the naphthalene units of PEN and the aromatic surface of the nanotubes [16]. For graphene, there have been some reports dealing with its good nucleating effect and its improvement of the electrical properties, upon adding very small quantities of graphene, in semicrystalline polymers such as polypropylene, polyethylene, nylon poly(vinylidene fluoride) (PVDF), and so forth [17-19].

PEN nanocomposites were prepared by melt blending with low wt $\%$ of graphene and crystallized nonisothermally. Although electrical conductivity of graphene-based PEN composites has been reported [20], no research has been done on the crystalline morphology and its influence on the properties of graphene-based PEN nanocomposites. Therefore, morphological changes and thermal and dielectric properties of PEN nanocomposites were investigated in detail in the present study at very low graphene content.

\section{Experimental}

2.1. Materials. Poly(ethylene naphthalate) homopolymer TEONEX ${ }^{\circledR}$ TN8085S with $M_{w}=42,921 \mathrm{~g} / \mathrm{gmol}$ from Teijin Chemicals LTD and graphene Nano Platelets HDPlas ${ }^{\mathrm{TM}}$ from Cheap Tubes Inc. were used in the experiments as received. The graphene platelets had an approximate diameter of $1-2 \mu \mathrm{m}$, surface area $>700 \mathrm{~m}^{2} / \mathrm{g},>99 \mathrm{wt} \%$ of purity, a number of layers higher than 4 , and low degree of defects according to the information obtained from RAMAN analysis of pristine graphene (see Supplementary Material available online at http://dx.doi.org/10.1155/2016/9846102).

2.2. Preparation of PEN-Graphene Nanocomposites. PEN and graphene were dried in a vacuum oven at $80^{\circ} \mathrm{C}$ overnight before preparing the nanocomposites. In order to increase the surface area of PEN pellets, they were pulverized down to a particle size of $100 \mu \mathrm{m}$. PEN was then mixed with different amounts of graphene: $0.01,0.025,0.05,0.075$, and $0.10 \mathrm{wt} \%$. The nanocomposites were obtained in a laboratory mini extruder model LME-120, from Polymer Testing, Ithaca, NY, USA. Samples were passed twice through the extruder at $300^{\circ} \mathrm{C}$ and $120 \mathrm{rpm}$.

After melt compounding, nanocomposites were compression molded at $300^{\circ} \mathrm{C}$ and $10 \mathrm{MPa}$ of pressure for 3 minutes, to obtain $1 \mathrm{~mm}$ thick samples, in order to eliminate any previous thermomechanical history. Finally, the samples were cooled down at $-10^{\circ} \mathrm{C} / \mathrm{min}$. These samples were used for further characterization.

\subsection{Characterization}

2.3.1. Differential Scanning Calorimetry (DSC). Crystallization and melting behavior of PEN-graphene nanocomposites was studied in a Perkin Elmer DSC 8500, from Perkin Elmer, Waltham, MA, USA, over the temperature range of 30$300^{\circ} \mathrm{C}$ under a nitrogen atmosphere. Samples were heated to $300^{\circ} \mathrm{C}$ at $10^{\circ} \mathrm{C} / \mathrm{min}$ and held there for $3 \mathrm{~min}$ to erase previous thermal history and then cooled to $30^{\circ} \mathrm{C}$ at $-10^{\circ} \mathrm{C} / \mathrm{min}$.

2.3.2. Wide Angle X-Ray Diffraction (WAXD) and Small Angle X-Ray Scattering Measurements (SAXS). Simultaneous WAXD and SAXS measurements of pure polymer and nanocomposites were measured at room temperature using an Anton Paar X-ray scattering equipment SAXSess $\mathrm{mc}^{2}$ from Anton Paar, Graz, Austria.

2.3.3. Fourier Transform Infrared Spectroscopy (FTIR). FTIR spectra of PEN and nanocomposites were obtained using a NICOLET 500 spectrometer, from Thermo Fisher, MA, USA, equipped with ATR unit. FTIR spectra were acquired (50 scans and $4 \mathrm{~cm}^{-1}$ resolution) from $4000-500 \mathrm{~cm}^{-1}$.

2.3.4. Optical Microscopy. Distribution of graphene platelets in the polymer matrix at the micrometric scale was analyzed in an Olympus BX60 microscope, from Olympus of the Americas, Center Valley, PA, USA, at 200x. The particle size analysis was performed by using the ImagePro software.

2.3.5. Transmission Electron Microscopy (TEM). The detailed morphology of nanocomposites was observed using a FEITITAN field emission microscope, from FEI North America, Hillsboro, OR, USA, with a voltage of $300 \mathrm{KV}$.

2.3.6. Capacitance Test. Dielectric properties were measured with a Keysight Precision LCR Meter model E4980A, from Keysight, Englewood, CO, USA, coupled with Keysight $16451 \mathrm{~B}$ dielectric test accessory at room temperature. Frequencies used were, of $0.1,1,10$, and $100 \mathrm{kHz}$. Each measurement was taken in quadruplicate and the average is reported as a result. The capacitance was determined by the parallel plate method according to ASTM D150-81.

\section{Results and Discussion}

3.1. Nonisothermal Crystallization. The presence of foreign particles in semicrystalline polymers during either isothermal or nonisothermal crystallization can modify the kinetics 
TABLE 1: DSC results of PEN/graphene nanocomposites with different graphene content.

\begin{tabular}{lccc}
\hline $\begin{array}{l}\text { Graphene content } \\
(\mathrm{wt} \%)\end{array}$ & $\begin{array}{l}T_{c}{ }^{\mathrm{a}} \\
\left({ }^{\circ} \mathrm{C}\right)\end{array}$ & $\begin{array}{l}T_{m}{ }^{\mathrm{b}} \\
\left({ }^{\circ} \mathrm{C}\right)\end{array}$ & $\begin{array}{l}\Delta T^{\mathrm{c}} \\
\left({ }^{\circ} \mathrm{C}\right)\end{array}$ \\
\hline 0 & 186.5 & 261.2 & 74.7 \\
0.010 & 193.9 & 263.3 & 69.4 \\
0.025 & 198.7 & 262.8 & 64.1 \\
0.050 & 200.7 & 263.1 & 62.4 \\
0.075 & 204.5 & 262.1 & 57.6 \\
0.100 & 204.4 & 260.7 & 56.3 \\
\hline
\end{tabular}

${ }^{\mathrm{a}}$ Crystallization peak temperature.

${ }^{\mathrm{b}}$ Melting peak temperature on the second heating.

${ }^{\mathrm{c}} \Delta T=T_{m}-T_{c}$ supercooling.

of the process. Depending on the characteristics of the particles such as the surface chemistry, morphology, size, and crystalline structure, these particles can act as nucleating agents [21, 22]. For PEN there is a nonextensive research on this topic compared to PET. However, there have been reported some substances that serve as heterogeneous nuclei and they initiate primary nucleation of PEN, or chemical nucleating agents, but all of them at higher contents to $0.1 \mathrm{wt} \%$ [23-26]. There have been a series of studies on the morphology, crystallization, and properties of PENcarbon nanotubes composites. It has been found that higher nanotubes contents to $0.1 \mathrm{wt} \%$ accelerate crystallization and increase the crystallization temperature $\left(T_{c}\right)[15,16,27,28]$. Figure 1 shows the cooling and heating thermograms of DSC at a rate of $10^{\circ} \mathrm{C} / \mathrm{min}$. It can be seen in Figure $1(\mathrm{a})$ that $T_{c}$ increases as a function of graphene content. In addition, it can be observed in Table 1 that the magnitude of increase of $T_{c}$, with increasing graphene content, decreases constantly and reaches a plateau at a graphene content of $0.1 \mathrm{wt} \%$, producing a $T_{c}$ of $\sim 204.5 \pm 0.5^{\circ} \mathrm{C}$. At this point the graphene nuclei may have reached the saturation point. The melting endotherms of Figure 1(b) show the appearance of a shoulder in nanocomposites with 0.075 and $0.1 \mathrm{wt} \%$ of graphene, corresponding to a second melting endotherm indicating a second crystal population. It may suggest that graphene as well as carbon nanotubes transmutes the crystallization of PEN, from the $\alpha$ form to the $\beta$ form [16].

Sorrentino et al. [29] studied the effect of expanded graphite (EG) on the crystallization and mechanical behavior of foamed PEN nanocomposites. During cooling from the molten state, they found an increase in $T_{c}$ of approximately $12^{\circ} \mathrm{C}$ at a maximum content of EG of $2.5 \mathrm{wt} \%$. In our case an increase of around $18^{\circ} \mathrm{C}$ in $T_{c}$ was observed, with graphene contents as low as $0.01 \mathrm{wt} \%$.

3.2. Crystalline Structure. The influence of graphene sheets on the PEN crystalline structure development was analyzed by means of WAXD. The relative crystallinity $\left(X_{c}\right)$ was calculated by means of the Murthy and Minor method [30]. It can be seen in Figure 2 that with very low graphene content PEN passes from an almost completely amorphous state to a semicrystalline polymer with $X_{c}$ around 29\% (Table 2). This phenomena indicates that graphene sheets act as effective nucleating particles for the crystallization of PEN. In this case, it is assumed that it is due to the structural similarity and the $\pi-\pi$ interactions between naphthalene rings and the hexagonal structure of graphene promoting conformational changes at the unit cell level. PEN typically develops two crystalline forms called $\alpha$ and $\beta$ [14]. The $\alpha$ form of PEN, which typically occurs as the polymer, is cooled down from the melt to the $T_{c}$ and the chain configuration is totally extended; $\beta$ form is developed when PEN is crystallized under some orientation process, in which case the unit cell contains not one but four chains of PEN in a kind of sinusoidal configuration. All PEN-graphene nanocomposites showed a mixture of $\alpha$ and $\beta$ crystalline forms. However, as shown in Figure 2, the $\alpha$ form tends to dominate at the lower graphene contents, but as the graphene content increases up to $0.10 \mathrm{wt} \%$, there is a transition and the $\beta$ form eventually dominates, as inferred from the disappearance of the (010), (100), and (110) diffraction peaks. This behavior has also been found in nonisothermally crystallized PEN-carbon nanotubes nanocomposites but at different filler contents $[16,31]$. The fraction of $\beta$ crystals was calculated according to the standard procedure described by Jones et al. [32] with the following equation:

$$
K_{\beta}=\frac{H_{\beta(\overline{11} 1)}+H_{\beta(020)}+H_{\beta(\overline{2} 02)}+H_{\beta(2 \overline{4} 2)}}{H_{\beta(\overline{11} 1)}+H_{\beta(020)}+H_{\beta(\overline{2} 02)}+H_{\beta(2 \overline{4} 2)}+H_{\alpha(010)}+H_{\alpha(100)}+H_{\alpha(\overline{1} 10)}}
$$

where $K_{\beta}$ is relative content of $\beta$-crystal form, $H_{\beta(\overline{11} 1)}, H_{\beta(020)}$, $H_{\beta(\overline{2} 02)}$, and $H_{\beta(2 \overline{4} 2)}$ are intensities of the strongest diffraction peaks of the triclinic $\beta$ form of PEN, and $H_{\alpha(010)}, H_{\alpha(100)}$, and $H_{\alpha(\overline{1} 10)}$ are intensities of the strongest peaks of $\alpha$-form of PEN.

From the quantitative point of view, as can be observed in Table 2, at very low graphene contents ( $0.01 \mathrm{wt} \%)$, almost $50 \%$ of crystals are related to the $\beta$-form crystals at very low graphene contents $(0.01 \mathrm{wt} \%)$ and they eventually dominate the crystalline phase at graphene contents from 0.05 to $0.1 \mathrm{wt} \%$.

According to the results, it can be suggested that the presence of a large amount of $\beta$-form crystals formed by the simple incorporation of graphene layers allows the easy preparation of nanocomposites with higher density and then with a marked increase in the mechanical properties according to the experimental correlations between the presence of these carbon nanostructures and the packaging characteristics, and the tensile strength reported by other authors $[33,34]$.

3.3. Lamellar Structure. SAXS studies were carried out in order to analyze the influence of graphene in the lamellar thickness of PEN crystals. It can be seen in Figure 3 that the pure PEN pattern does not show any characteristic signal of 


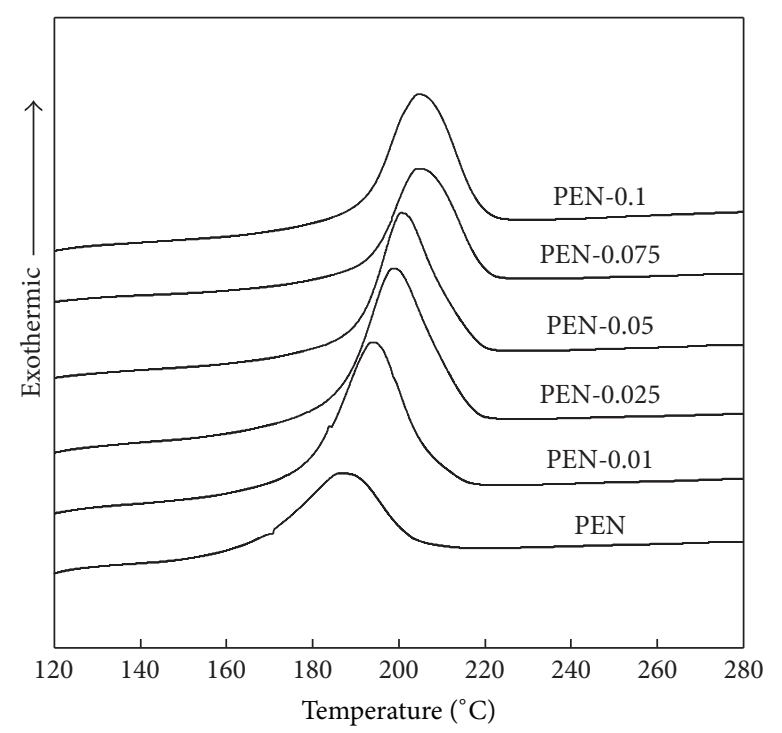

(a)

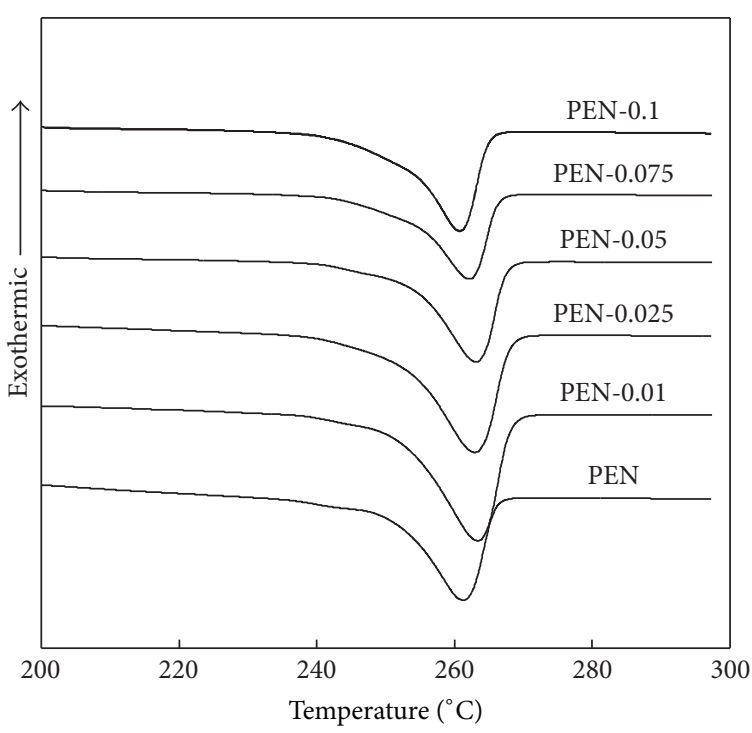

(b)

FIGURE 1: DSC scans for thermograms of the PEN and PEN nanocomposites at different graphene content during (a) cooling and (b) heating at $10^{\circ} \mathrm{C} / \mathrm{min}$.

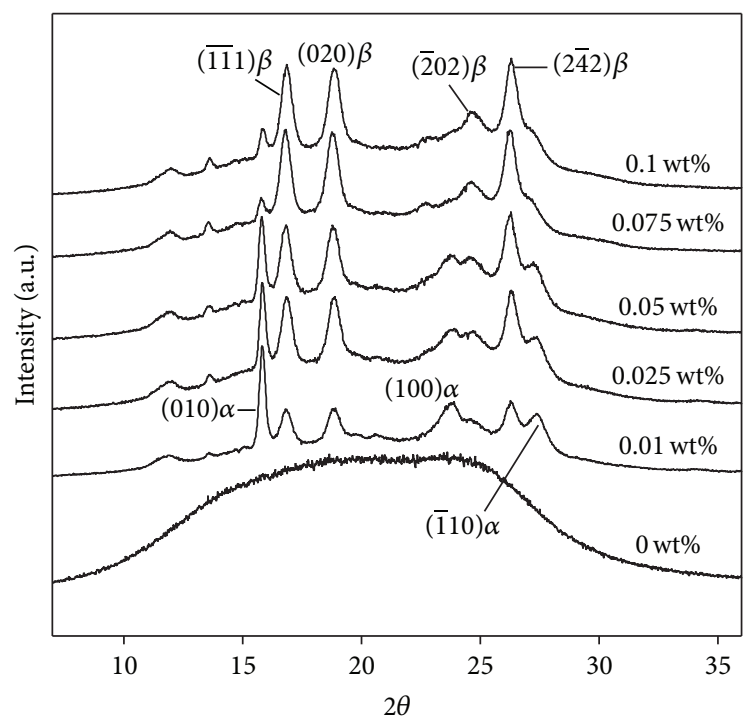

FIGURE 2: WAXD patterns of pure PEN and PEN-graphene nanocomposites.

TABLE 2: Relative crystallinity ( $\% X_{c}$ ) of PEN-graphene nanocomposites and fraction of $\beta$ crystals.

\begin{tabular}{lcccccc}
\hline Graphene $(\mathrm{wt} \%)$ & 0 & 0.01 & 0.025 & 0.05 & 0.075 & 0.1 \\
\hline$X_{c}(\%)$ & - & 26.9 & 29.7 & 28.2 & 27.6 & 25.6 \\
Fraction of $\beta$ & - & 0.41 & 0.62 & 0.70 & 0.91 & 0.92 \\
\hline
\end{tabular}

the presence of lamellar structures. With the incorporation of low quantities of graphene, however, the ordering of PEN molecules is induced and lamellar crystals are formed, as indicated by the increasing shoulder at $q \sim 0.15(1 / \mathrm{nm})$. As

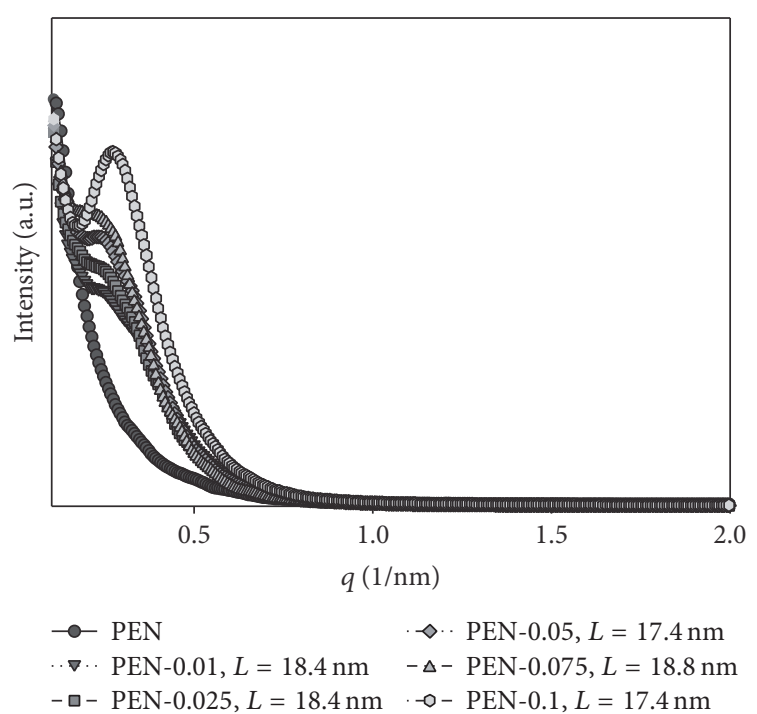

FIgURE 3: Experimental SAXS patterns of pure PEN and nanocomposites.

can be observed, the crystal size $(L)$ of PEN in nanocomposites remains quite unchanged even when there is a transition in crystals type from $\alpha$ to $\beta$. However, a narrower crystal size distribution can be seen in nanocomposites with $0.1 \mathrm{wt} \%$ of graphene. This may be assumed to be because at $0.1 \mathrm{wt} \%$ of graphene the surface area of particles is the adequate to induce almost a total $\alpha$ to $\beta$ change in crystalline morphology of PEN.

3.4. Conformational Changes. As observed in WAXD results, graphene induces changes at the unit cell level in PEN 


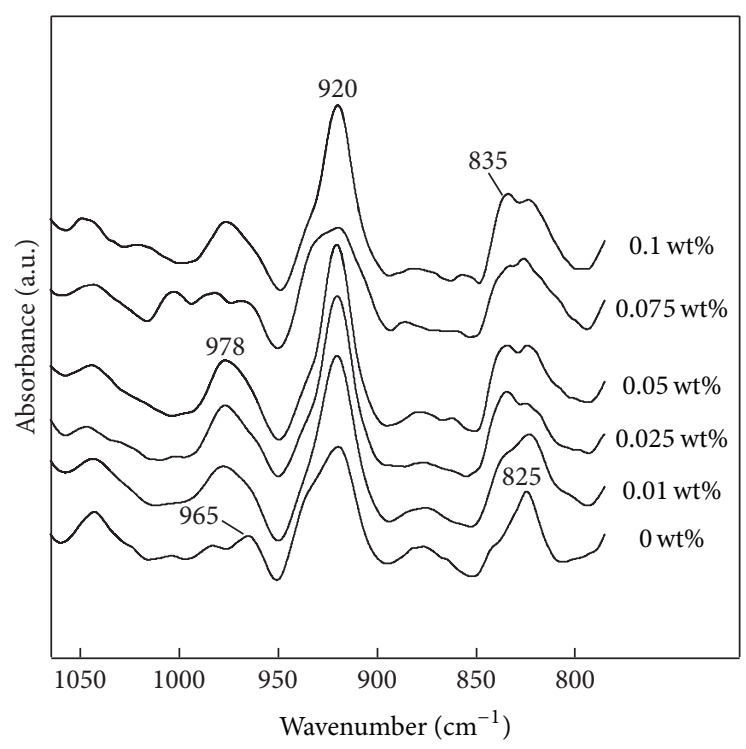

FIGURE 4: FTIR spectra of PEN and PEN-graphene nanocomposites nonisothermally crystallized.

molecules. These changes are promoted by means of conformational changes during crystallization, and the final arrangement of the PEN chains can be verified by infrared spectroscopy. The phenomenon of clay-induced polymorphism in PEN-clay nanocomposites has been reported [35]. In this case, the authors found that the type of crystal phase that forms during PEN crystallization depends on the surfactant molecules and their degradation products at the polymer/organoclay interface. In the case of PEN-graphene nanocomposites the hexagonal structure of graphene particles and aromaticity of PEN may play an important role during nucleation due to some aspects such as the lack of functional groups in the surface of graphene that avoid a steric hindrance for the adsorption of PEN molecules, the semiplanarity of PEN molecules, and $\pi-\pi$ interactions between PEN and graphene surface. Figure 4 shows representative FTIR spectra of PEN and PEN nanocomposites nonisothermally crystallized. The region between 1000 and $800 \mathrm{~cm}^{-1}$ was particularly analyzed. For pure PEN some peaks characteristic of the amorphous phase appear at 825 and $965 \mathrm{~cm}^{-1}$ [36]. The appearance of new peaks in PEN nanocomposites is assumed to be due to the conformational changes induced by the interactions between PEN molecules and graphene surface during the nonisothermal crystallization process.

It can be seen that the FTIR spectra of nanocomposites show the signals of both, the $\alpha$ and $\beta$ crystalline forms. Also, as the graphene content increases, the $\beta$ crystalline form becomes amply dominant, as indicated by the marked and well defined signals at 835,920 , and $978 \mathrm{~cm}^{-1}$. This coincides with the data in Table 2 , where the $\beta$ crystalline form passes from being $40 \%$ of the whole crystalline phase, at $0.010 \mathrm{wt} \%$ graphene content, to $90 \%$ at $0.10 \mathrm{wt} \%$ graphene content.

Due to the mixture of $\alpha$ and $\beta$ crystals, the FTIR spectra of nanocomposites show the signals of both crystalline forms. However, due to the increase in graphenic nuclei, the $\beta$ peaks are well defined at 835,920 , and $9781 / \mathrm{cm}$. It indicates important changes in the conformation of PEN molecules, from $\alpha$ all-trans conformation to both $\beta$ trans and gauche conformations where the $\beta$ crystals population dominates.

3.5. Distribution and Dispersion of Graphene Particles in PEN Nanocomposites. In order to analyze the distribution of graphene particles in PEN nanocomposites at microscopic level samples were studied in an optical microscope. Figure 5 shows the distribution of graphene in the different nanocomposites. It can be seen in all cases that graphene particles are very well distributed and the average particle size was found to be around $1.5-2 \mu \mathrm{m}$. Continuing with this analysis, the morphology of graphene at a minor scale was carried out by means of TEM. Figure 6 shows a homogeneous dispersion in all nanocomposites. Also, it can be seen that graphene layers are partially exfoliated which can explain the good nucleating activity of graphene for PEN crystallization without the use of compatibilizers, ultrasound, or chemical modification of graphene as reported by other authors [20].

3.6. Dielectric Properties. Figure 7 shows the values of permittivity or dielectric constants of PEN and PEN-graphene nanocomposites at different frequencies. It is observed that the dielectric constant of processed PEN is around 1.9 at different frequencies. When graphene is added to PEN, the dielectric constants tend to increase up to 3.0 at $0.075 \mathrm{wt} \%$ of graphene, which is approximately twice that of the PEN dielectric constant. But as graphene content was increased to $0.1 \mathrm{wt} \%$, however, the dielectric constant decreased. In this case, it has been reported [37] that some polymers tend to store some mobile charges such as phonons and electrons at low graphene contents, which produces an increase in the dielectric constant of polymer nanocomposites. As the graphene content increases, the dielectric constant decreases due to the accumulation of charge in the graphenePEN interphase. At this point the charges start to present 


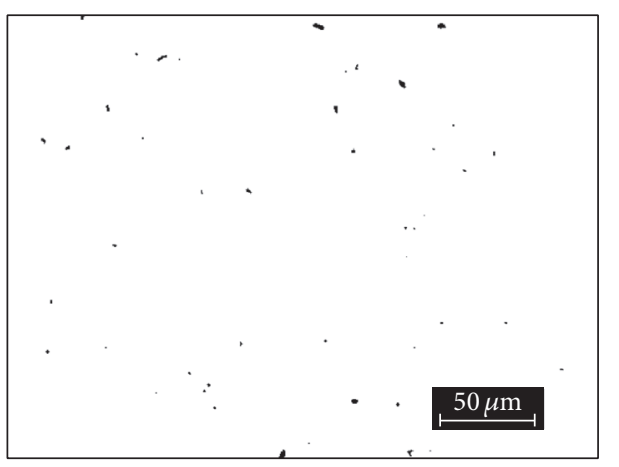

(a)

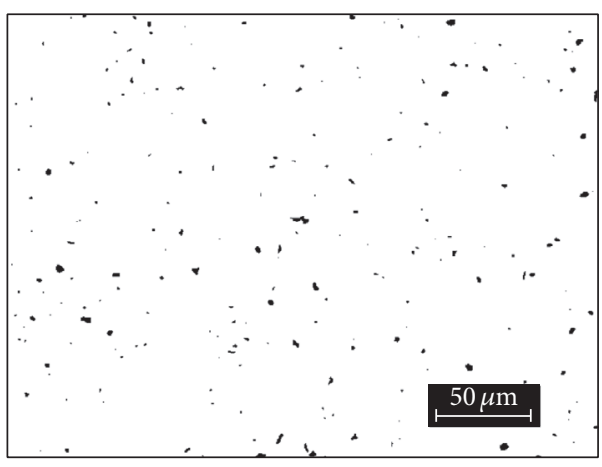

(c)

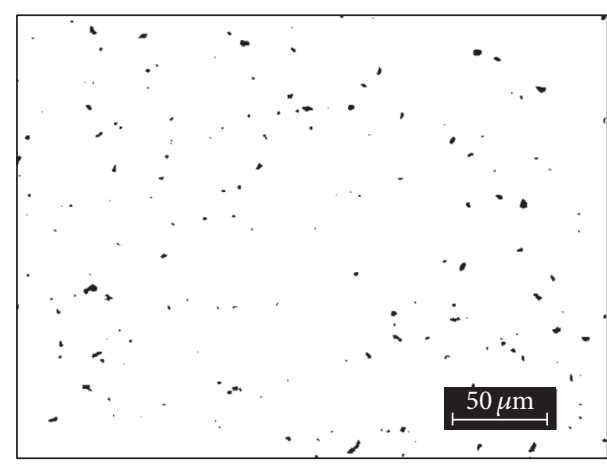

(b)

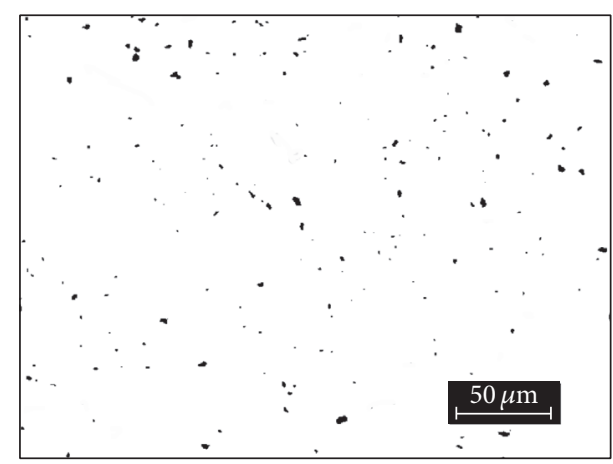

(d)

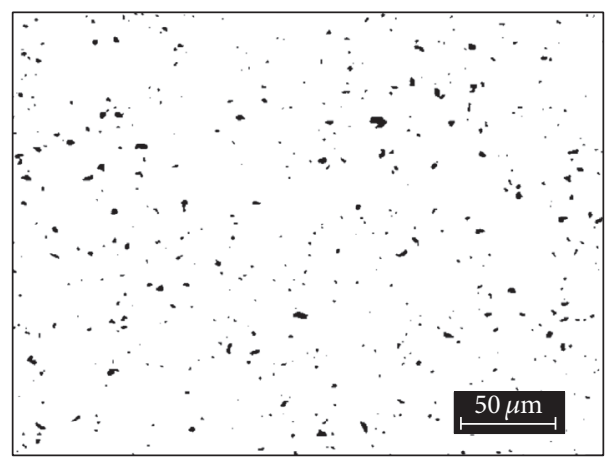

(e)

FIGURE 5: Images from the optical microscope of the dispersion of PEN-graphene nanocomposites with different contents of graphene: (a) 0.01 , (b) 0.025 , (c) 0.05 , (d) 0.075 , and (e) $0.1 \mathrm{wt} \%$.

an increasing mobility, which eventually gives rise to the percolation phenomenon. In a few words by varying the graphene concentration it is possible to control dielectric constant of polymeric nanocomposites and they may serve as charge storing devices of low electric charge, for example, in microbial fuel cells or other organic bioelectricity sources [38].

\section{Conclusions}

The crystalline morphology changes and the dielectric properties of nonisothermally crystallized PEN-graphene nanocomposites were investigated. Results indicate that graphene induces PEN crystallization at very low graphene contents, from 0.01 to $0.1 \mathrm{wt} \%$. According to the DSC analyses, $T_{c}$ showed a marked increase of up to $18^{\circ} \mathrm{C}$ supporting the high nucleating activity of graphene particles due to the structural similarity between the naphthalene rings of PEN and the graphene surface and $\pi-\pi$ interactions. WAXD, SAXS, and FTIR clearly indicated that graphene modifies the conformation of PEN molecules during crystallization promoting the evolution from $\alpha$ to $\beta$ crystalline form with a homogeneous thickness distribution in crystals population, which is preferred at $0.1 \mathrm{wt} \%$ of graphene. Distribution and dispersion of graphene were homogeneous in all nanocomposites and intercalation-exfoliation of graphene layers without the use of compatibilizers, ultrasound, or chemical modification of graphene was reasonably good. 


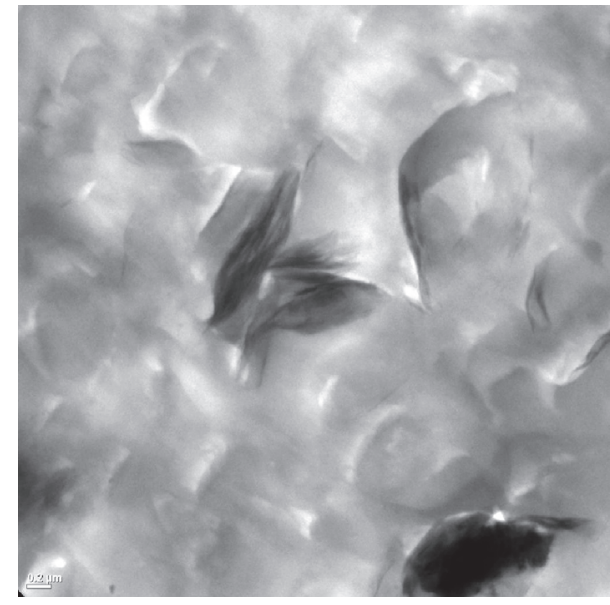

(a)

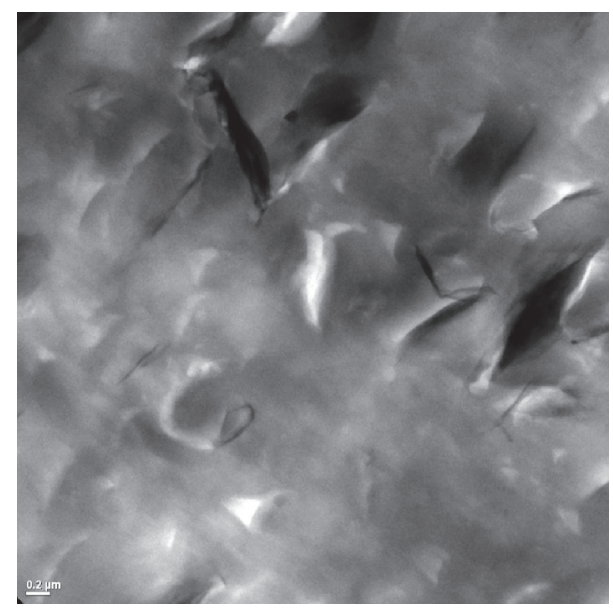

(c)

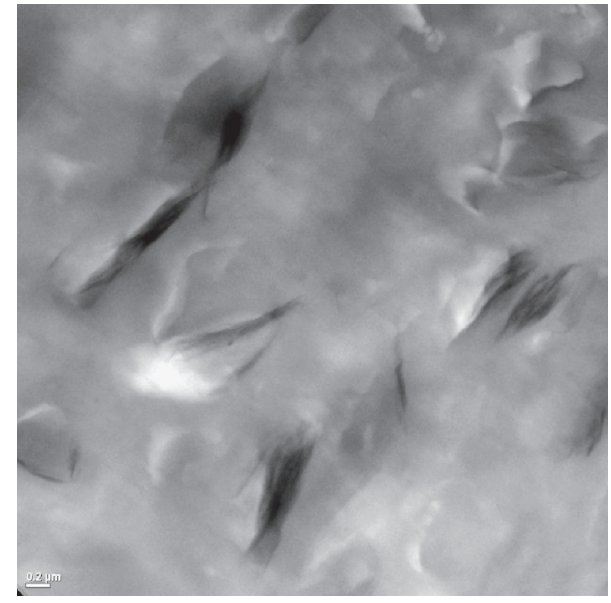

(b)

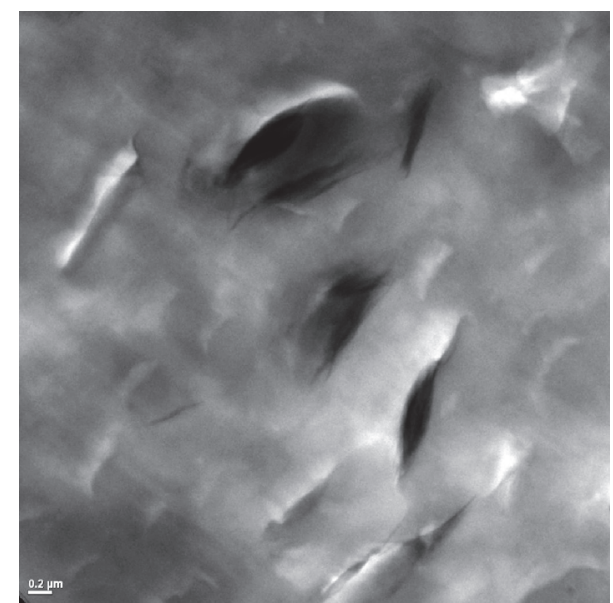

(d)

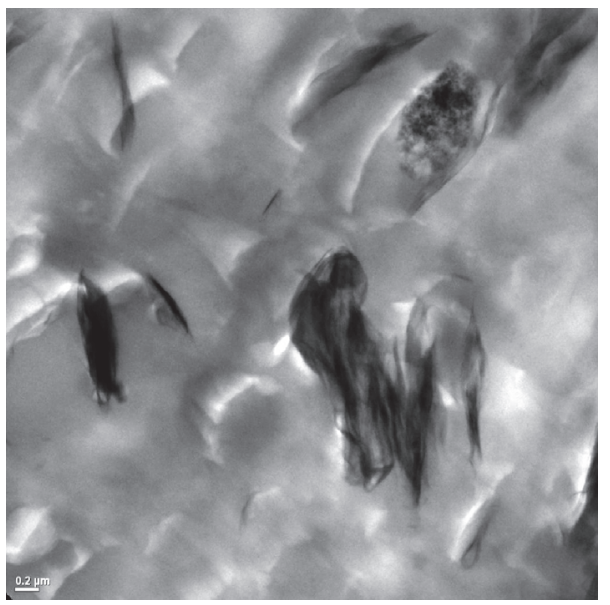

(e)

FIGURE 6: TEM images of PEN-graphene nanocomposites with different contents of graphene: (a) 0.01, (b) 0.025 , (c) 0.05 , (d) 0.075 , and (e) $0.1 \mathrm{wt} \%$. 


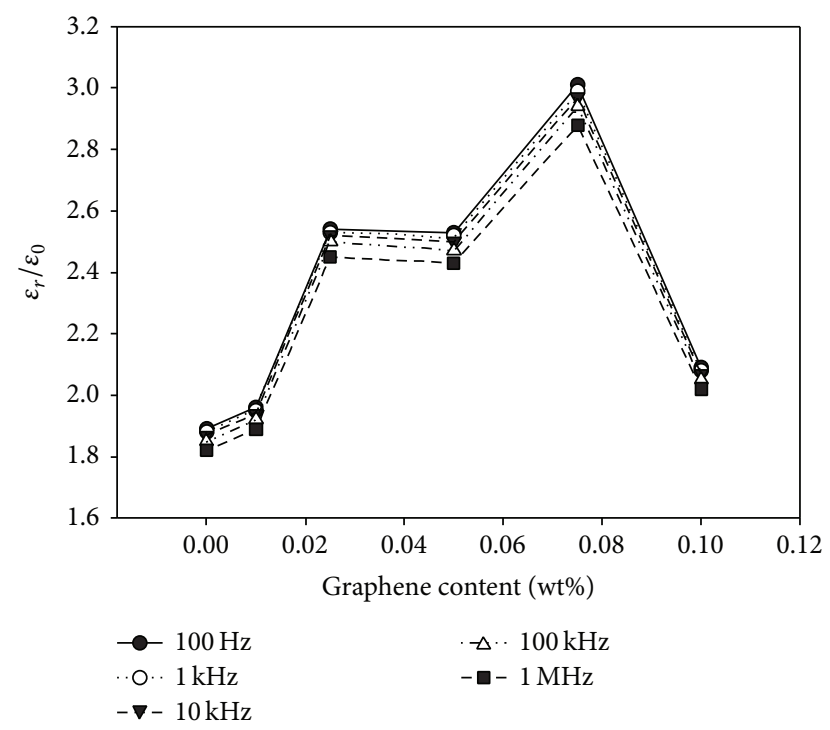

FIgURE 7: Permittivity of PEN and PEN-graphene nanocomposites nonisothermally crystallized at different frequencies and with different graphene content.

Finally, the dielectric behavior of PEN-graphene nanocomposites changes as a function of graphene content, changing from dielectric to a low conducting material when passing from 0.075 to $0.1 \mathrm{wt} \%$ of graphene.

\section{Competing Interests}

The authors declare that they have no competing interests.

\section{Acknowledgments}

One of the authors (Pedro A. Espinoza-Martinez) thanks CONACYT for granting him scholarship to carry his M.S. studies. Also, the authors gratefully acknowledge the financial support through Projects CIQA-6162 and CONACYT-CB222805 and CONACYT-LN-232753. Also the authors wish to thank Marcelina Sánchez, Silvia Torres, Julieta Sánchez, Gilberto Hurtado, Josefina Zamora, Adán Herrera, Jesús Cepeda, Myriam Lozano, and Enrique Barriga for their technical support.

\section{References}

[1] A. K. Geim and K. S. Novoselov, "The rise of graphene," Nature Materials, vol. 6, no. 3, pp. 183-191, 2007.

[2] C. Bora, P. Bharali, S. Baglari, S. K. Dolui, and B. K. Konwar, "Strong and conductive reduced graphene oxide/polyester resin composite films with improved mechanical strength, thermal stability and its antibacterial activity," Composites Science and Technology, vol. 87, pp. 1-7, 2013.

[3] J.-Y. Kwon and H.-D. Kim, "Preparation and properties of acidtreated multiwalled carbon nanotube/waterborne polyurethane nanocomposites," Journal of Applied Polymer Science, vol. 96, no. 2, pp. 595-604, 2005.
[4] K. Hu, D. D. Kulkarni, I. Choi, and V. V. Tsukruk, "Graphenepolymer nanocomposites for structural and functional applications," Progress in Polymer Science, vol. 39, no. 11, pp. 1934-1972, 2014.

[5] T. K. Gupta, B. P. Singh, R. B. Mathur, and S. R. Dhakate, "Multi-walled carbon nanotube-graphene-polyaniline multiphase nanocomposite with superior electromagnetic shielding effectiveness," Nanoscale, vol. 6, no. 2, pp. 842-851, 2014.

[6] M. C. Costache, M. J. Heidecker, E. Manias, and C. A. Wilkie, "Preparation and characterization of poly(ethylene terephthalate)/clay nanocomposites by melt blending using thermally stable surfactants," Polymers for Advanced Technologies, vol. 17, no. 9-10, pp. 764-771, 2006.

[7] J. M. Zhang, C. T. Reynolds, and T. Peijs, "All-poly(ethylene terephthalate) composites by film stacking of oriented tapes," Composites Part A: Applied Science and Manufacturing, vol. 40, no. 11, pp. 1747-1755, 2009.

[8] G. S. Deshmukh, D. R. Peshwe, S. U. Pathak, and J. D. Ekhe, "Evaluation of mechanical and thermal properties of Poly (butylene terephthalate) (PBT) composites reinforced with wollastonite," Transactions of the Indian Institute of Metals, vol. 64, no. 1-2, pp. 127-132, 2011.

[9] A. R. Mackintosh and J. J. Liggat, "Dynamic mechanical analysis of poly(trimethylene terephthalate)? A comparison with poly(ethylene terephthalate) and poly(ethylene naphthalate)," Journal of Applied Polymer Science, vol. 92, no. 5, pp. 2791-2796, 2004.

[10] L.-J. Zheng, J.-G. Qi, Q.-H. Zhang, W.-F. Zhou, and D. Liu, "Crystal morphology and isothermal crystallization kinetics of short carbon fiber/poly(ethylene 2,6-naphthalate) composites," Journal of Applied Polymer Science, vol. 108, no. 1, pp. 650-658, 2008.

[11] W. MacDonald, "Handbook of thermoplastic polyesters, vols 1 and $2 \mathrm{~S}$ Fakirov Weinheim, Wiley-VCH, 2002 Vol 1 pp 753, ISBN 3-527-29790-1 Vol 2 pp 624, ISBN 3-527-30113-5," Polymer International, vol. 52, no. 5, pp. 859-860, 2003.

[12] W. D. Lee, E. S. Yoo, and S. S. Im, "Crystallization behavior and morphology of poly(ethylene 2,6-naphthalate)," Polymer, vol. 44, no. 21, pp. 6617-6625, 2003.

[13] S. Murakami, Y. Nishikawa, M. Tsuji, A. Kawaguchi, S. Kohjiya, and M. Cakmak, "A study on the structural changes during uniaxial drawing and/or heating of poly(ethylene naphthalene2,6-dicarboxylate) films," Polymer, vol. 36, no. 2, pp. 291-297, 1995.

[14] J. Liu, G. Sidoti, J. A. Hommema, P. H. Geil, J. C. Kim, and M. Cakmak, "Crystal structures and morphology of thin-film, melt-crystallized, and polymerized poly(ethylene naphthalate)," Journal of Macromolecular Science-Physics, vol. 37, no. 4, pp. 567-586, 1998.

[15] J. Y. Kim, S.-I. Han, and S. H. Kim, "Crystallization behaviors and mechanical properties of polyethylene 2,6naphthalate/multiwall carbon nanotube nanocomposites," Polymer Engineering and Science, vol. 47, no. 11, pp. 1715-1723, 2007.

[16] A. B. Espinoza-Martınez, J. M. M.-P. Francisco, and J. MedellınRodriguez, "Effect of MWNTs concentration and cooling rate on the morphological, structural, and electrical properties of non-isothermally crystallized PEN/MWNT nanocomposites," Journal of Applied Polymer Science, vol. 132, no. 14, p. 41765, 2015.

[17] J.-Z. Xu, Y.-Y. Liang, H.-D. Huang et al., "Isothermal and nonisothermal crystallization of isotactic polypropylene/graphene oxide nanosheet nanocomposites," Journal of Polymer Research, vol. 19, no. 10, article 9975, 2012. 
[18] R. K. Layek, S. Samanta, D. P. Chatterjee, and A. K. Nandi, "Physical and mechanical properties of poly(methyl methacrylate) -functionalized graphene/poly(vinylidine fluoride) nanocomposites: piezoelectric $\beta$ polymorph formation," Polymer, vol. 51, no. 24, pp. 5846-5856, 2010.

[19] S. Ansari and E. P. Giannelis, "Functionalized graphene sheetPoly(vinylidene fluoride) conductive nanocomposites," Journal of Polymer Science, Part B: Polymer Physics, vol. 47, no. 9, pp. 888-897, 2009.

[20] H. Kim and C. W. Macosko, "Morphology and properties of polyester/exfoliated graphite nanocomposites," Macromolecules, vol. 41, no. 9, pp. 3317-3327, 2008.

[21] F. L. Binsbergen, "Natural and artificial heterogeneous nucleation in polymer crystallization," Journal of Polymer Science Part B: Polymer Physics, vol. 59, no. 1, pp. 11-29, 1976.

[22] J. C. Wittmann and B. Lotz, "Epitaxial crystallization of polymers on organic and polymeric substrates," Progress in Polymer Science, vol. 15, no. 6, pp. 909-948, 1990.

[23] X. Gao,, M. Jin,, and H. Bu,, "Influence of additives on crystallization of poly(ethylene 2,6-naphthalate)," Journal of Macromolecular Science-Physics, vol. 40, no. 1, pp. 69-81, 2001.

[24] X. Gao, R. Liu, M. Jin, and H. Bu, "Crystallization and morphology of poly(ethylene-2,6-naphthalene dicarboxylate) in the presence of nucleating agents," Journal of Polymer Science, Part B: Polymer Physics, vol. 40, no. 20, pp. 2387-2394, 2002.

[25] X. Gao, R. Liu, J. Zhang, and J. Zhang, "Crystallization behaviors of poly(ethylene 2,6-naphthalate) in the presence of liquid crystalline polymer," Industrial and Engineering Chemistry Research, vol. 47 , no. 8, pp. 2590-2596, 2008.

[26] X. Gao, M. Jin, and H. Bu, "Crystallization of poly(ethylene 2,6naphthalate) containing additives," Journal of Polymer Science, Part B: Polymer Physics, vol. 38, no. 24, pp. 3285-3288, 2000.

[27] J. Y. Kim, S. I. Han, and S. Hong, "Effect of modified carbon nanotube on the properties of aromatic polyester nanocomposites," Polymer, vol. 49, no. 15, pp. 3335-3345, 2008.

[28] J. Y. Kim, H. S. Park, and S. H. Kim, "Unique nucleation of multi-walled carbon nanotube and poly(ethylene 2,6naphthalate) nanocomposites during non-isothermal crystallization," Polymer, vol. 47, no. 4, pp. 1379-1389, 2006.

[29] L. Sorrentino, M. Aurilia, L. Cafiero, S. Cioffi, and S. Iannace, "Mechanical behavior of solid and foamed polyester/expanded graphite nanocomposites," Journal of Cellular Plastics, vol. 48, no. 4 , pp. 355-368, 2012.

[30] N. S. Murthy and H. Minor, "General procedure for evaluating amorphous scattering and crystallinity from X-ray diffraction scans of semicrystalline polymers," Polymer, vol. 31, no. 6, pp. 996-1002, 1990.

[31] J. Y. Kim, S. I. Han, D. K. Kim, and S. H. Kim, "Mechanical reinforcement and crystallization behavior of poly(ethylene 2,6naphthalate) nanocomposites induced by modified carbon nanotube," Composites Part A: Applied Science and Manufacturing, vol. 40, no. 1, pp. 45-53, 2009.

[32] A. T. Jones, J. M. Aizlewood, and D. R. Beckett, "Crystalline forms of isotactic polypropylene," Die Makromolekulare Chemie, vol. 75, no. 1, pp. 134-158, 1964.

[33] M. Cakmak and J. C. Kim, "Structure development in highspeed spinning of polyethylene naphthalate (PEN) fibers," Journal of Applied Polymer Science, vol. 64, no. 4, pp. 729-747, 1997.
[34] K. Miyata, H. Ito, T. Kikutani, and N. Okui, "Structural change of high-speed spun poly(ethylene 2,6-naphthalene dicarboxylate) fibers with annealing," Sen'i Gakkaishi, vol. 55, no. 11, pp. 542-551, 1999.

[35] Y. C. Chua, X. Lu, and T. Wan, "Polymorphism behavior of poly(ethylene naphthalate)/clay nanocomposites," Journal of Polymer Science, Part B: Polymer Physics, vol. 44, no. 7, pp. 10401049, 2006

[36] Y. C. Chua and X. Lu, "Polymorphism behavior of poly(ethylene naphthalate)/clay nanocomposites: role of clay surface modification," Langmuir, vol. 23, no. 4, pp. 1701-1710, 2007.

[37] R. Perumal Ramasamy, K. Yang, and M. H. Rafailovich, "Polypropylene-graphene-a nanocomposite that can be converted into a meta-material at desired frequencies," RSC Advances, vol. 4, no. 85, pp. 44888-44895, 2014.

[38] B. E. Logan, "Exoelectrogenic bacteria that power microbial fuel cells," Nature Reviews Microbiology, vol. 7, no. 5, pp. 375-381, 2009. 

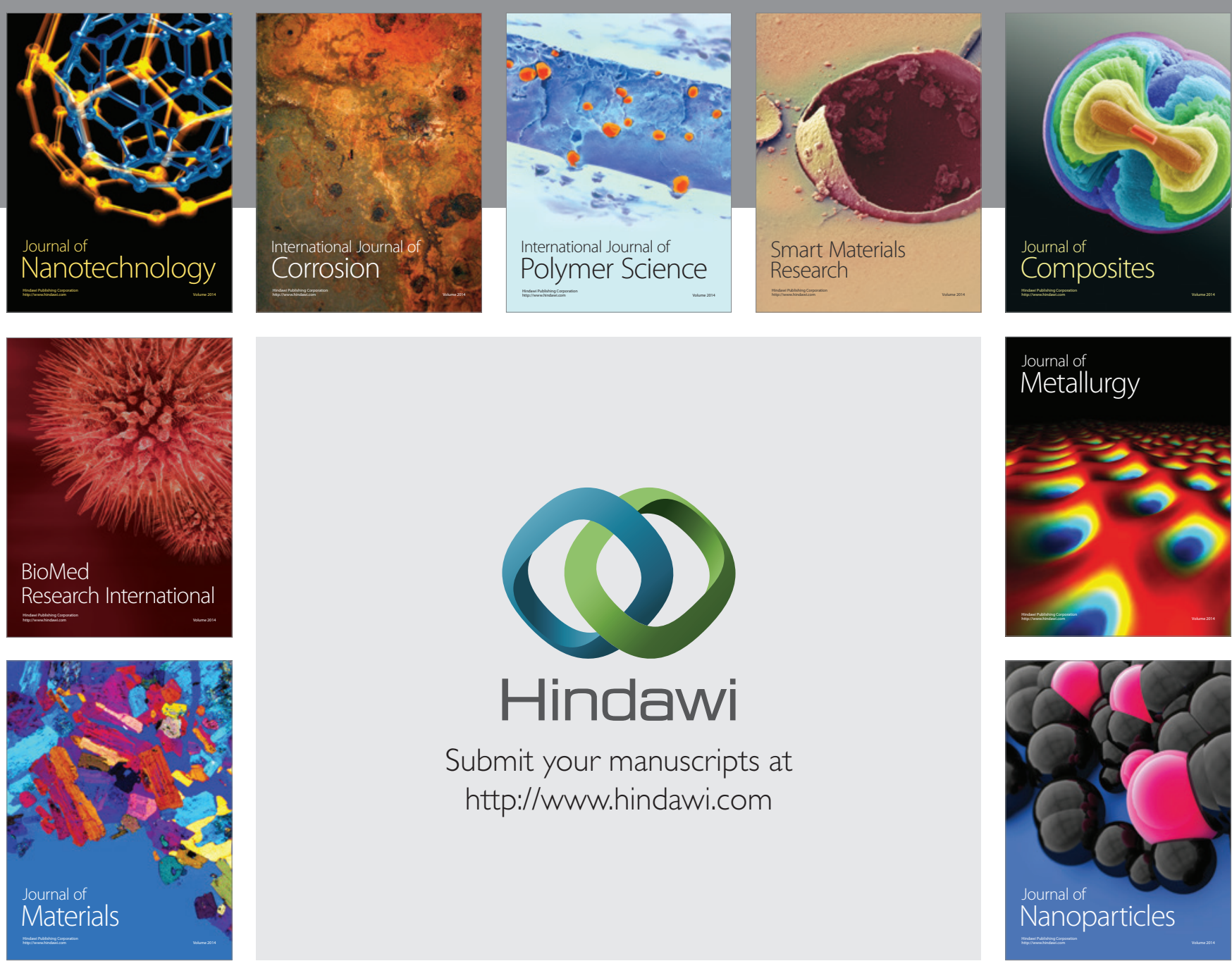

\section{Hindawi}

Submit your manuscripts at

http://www.hindawi.com

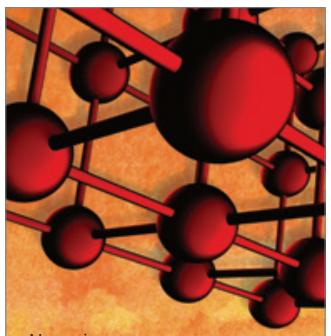

Materials Science and Engineering
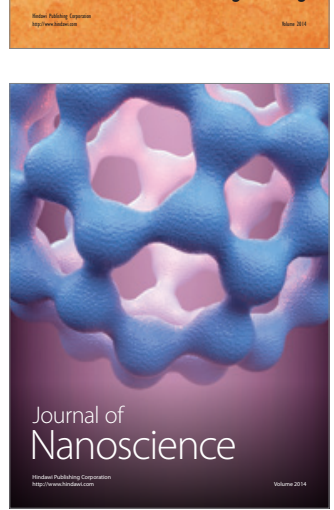
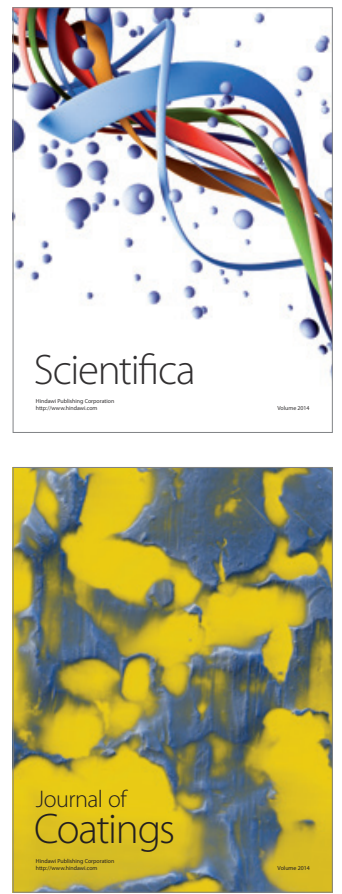
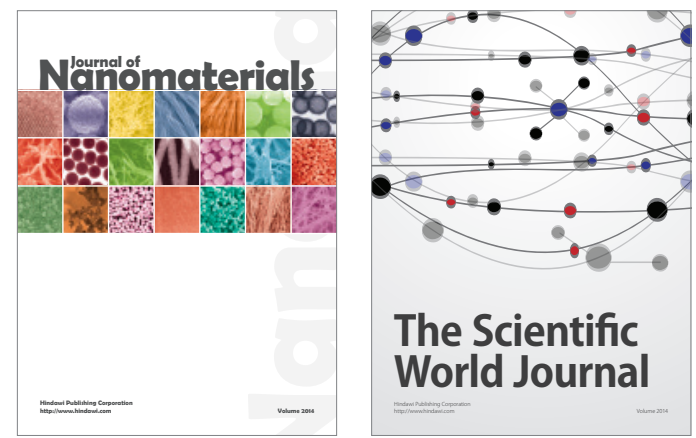

The Scientific World Journal
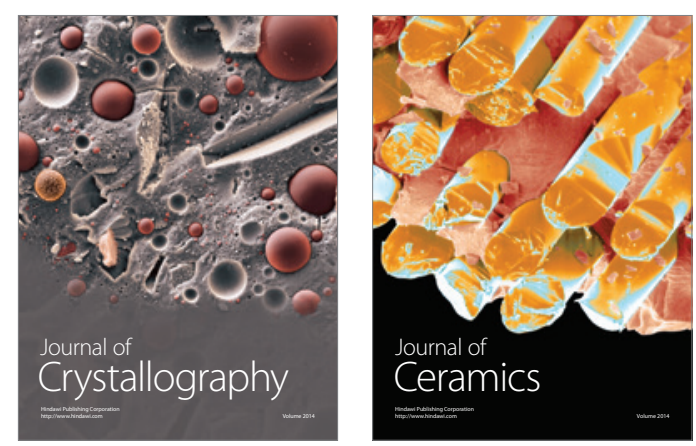
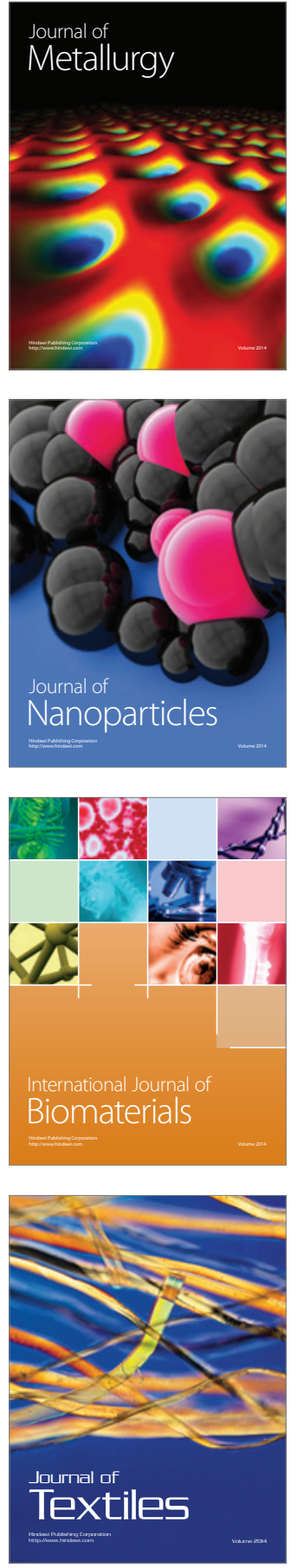